\title{
The Ecosystem Approach as a Basis for Managerial Compliance: An Example from the Regulatory Development in the Baltic Sea Region
}

\author{
Brita Bohman
}

1

Introduction

Managerial compliance is a concept that was introduced in international law in the 1990s as an alternative view on how and why states comply with international agreements. ${ }^{1}$ The basic idea in this view on compliance is that states want to comply with international agreements, and do so, if given the right prerequisites and support rather than if they are sanctioned for non-compliance, i.e. if being given 'carrots' instead of 'sticks'. In short, this perspective on compliance and state behaviour includes the theory that encouragement and factors such as technical and financial resources, and administrative support in developing regulatory approaches or implementation measures, are more rewarding in terms of compliance than different forms of sanctions or hard rules. $^{2}$ This perspective on compliance can be especially useful in environmental law since complex environmental problems often entail difficulties in defining effective measures and assessing results, implying that it is difficult to determine the exact meaning of compliance from a strict objective point of view. ${ }^{3}$

Eutrophication in the Baltic Sea has, since the 1970s, primarily been regulated by the Convention on the Protection of the Marine Environment of the Baltic Sea Area 4 (the Helsinki Convention) and the Baltic Marine Environment Protection Commission (HELCOM). This regulatory regime has often been seen as weak and with a rather high level of alleged non-compliance by the Parties. In

1 A Chayes and AH Chayes, The New Sovereignty: Compliance with International Regulatory Agreements (Harvard University Press 1995).

2 See e.g. D Bodansky, The Art and Craft of International Environmental Law (Harvard University Press 2010) 235-45.

3 B Bohman, Transboundary Law for Social-Ecological Resilience? - A Study on Eutrophication in the Baltic Sea Area (Stockholm University US-AB 2017) 316-21. See also Bodansky (n 2 ) $250-51$.

41507 UNTS 167.

(C) BRITA BOHMAN, 2019 | DOI:10.1163/9789004389984_004

This is an open access chapter distributed under the terms of the prevailing CC-BY-NC License at the time of publication. 
the early 2000 s the ecosystem approach was introduced along with a general change in the regulatory structure for the Baltic Sea environment and in the approach to reducing eutrophication. Beside the generally acknowledged difficulties of creating a regulatory system which is based on ecological indicators, it is also widely debated what an ecosystem approach entails in a regulatory system in terms of legal measures and mechanisms, as this book shows. It is even debated whether an ecosystem approach can be implemented with any real success. ${ }^{5}$

This chapter aims to describe the regulatory structure for abating eutrophication that has developed in the Baltic Sea region with the implementation of the ecosystem approach and how it reflects characteristics typical for managerial compliance review. The main purpose is to show, based on a previous study, how the implementation of an ecosystem approach has not only established a more ecosystem-focused legal system for the Baltic Sea, it has also strengthened enforcement and the general compliance with the given regulatory instruments. ${ }^{6}$

In the Baltic Sea region the introduction of the ecosystem approach occurred with and in parallel to the European Union's (EU) adoption of the Marine Strategy Framework Directive ${ }^{7}$ (the MSFD). This regulatory change was also connected to the 2007 HELCOM Baltic Sea Action Plan (BSAP), which is a regional reflection of the MSFD. The MSFD also introduced the goal of good environmental status to the marine regulatory governance in the Baltic Sea region. Pursuit of this goal has resulted in the initiation of a process whereby the coastal states cooperate to identify ecological indicators and continuously assess the ecosystem status. The process also includes adaptive reassessment of measures and other dynamic regulatory developments. This regulatory change and the operationalization of this adaptive process has encountered challenges, such as institutional coordination, flexible requirements that are

5 E.g. V De Lucia, 'Competing Narratives and Complex Genealogies: The Ecosystem Approach in International Environmental Law' (2015) $27 \mathrm{~J}$ Env L 91.

6 The discussion in this chapter is to a large extent based on a wider study made by the author in her PhD dissertation: Bohman ( $\mathrm{n} 3$ ). Some of the reasoning will thus only be referring to more far-reaching analysis and argumentation made in the original study and will not be repeated here.

7 Directive 2008/56/EC of 17 June 2008 establishing a framework for community action in the field of marine environmental policy (the Marine Strategy Framework Directive) OJ L164/19. 
hard to enforce, and, not least, the complexity of ecosystem factors. Many of these challenges remain to be resolved. However, it has also led to an important shift in the regulatory focus and institutional structure.

Through the ecosystem approach and the goal of good environmental status the applicable regulatory instruments have integrated a regulatory approach that is directly related to the status of the ecosystem. The most significant result of this is the acknowledgment of reduction targets in the BSAP, which correspond to the goal of good environmental status. Although the reduction targets are not binding, as such, they concretize the goal and have raised the bar for state implementation. This has also been important in bringing transboundary cooperation and an adaptive process forward, and thus in creating a structure that seems to be able to foster a more steady basis for transboundary cooperation with continuous focus on both compliance and ecosystem-based measures. This new structure integrates features that could be seen as representing an ecosystem approach in a more general perspective, this includes features that reflect the kind of adaptive measures that are typically connected with an ecosystem approach, but also other features that may bridge and compensate for some of the inherent gaps and challenges related to applying the concept in a legal context and in integrating it in the legal system, as referred to above. The assumption that these latter features will bring a positive effect to the general structure and bridge the institutional challenges is based in the research on theories for so-called social-ecological resilience. This research emphasizes certain functions or mechanisms that support effective environmental governance, mechanisms which can also been identified in this regulatory structure. ${ }^{8}$ It is also evident from the example of regulating eutrophication in the Baltic Sea that this combination of features bring important functions to a regulatory structure that has previously shown significant weakness and lack of authority in controlling compliance. Such weaknesses could also have become even worse when implementing an ecosystem approach if it would have only entailed more flexibility and adaptive approaches.

In this chapter, different features of ecosystem approach in the legal context will be presented and discussed. These features are based on, and reflect, important components for governance emphasized in the theories on social-ecological resilience, which is an important theoretical view point for

8 R Biggs, M Schlüter and ML Schoon (eds), Principles for Building Resilience - Sustaining Ecosystem Services in Social-Ecological Systems (Cambridge University Press 2015); FS Chapin III, GP Kofinas and C Folke (eds), Principles of Ecosystem Stewardship - Resilience-Based Natural Resource Management in a Changing World (Springer 2009). See also Bohman (n 3 ) 36-55. 
the understanding of the ecosystem approach. These features are - with support in the underlying theories - more concrete than the general principles of ecosystem approach, but share the same aim of governance. Therefore the features of governance for social-ecological resilience are taken as an example to show how an ecosystem approach can be understood in relation to law and legal mechanisms. They will moreover show how different pieces of a structure for ecosystem governance also within a legal system can balance each other and thus create a more complete and effective structure, establishing processes with important elements for effective implementation and compliance in relation to such a complex problem as eutrophication.

\section{The Ecosystem Approach}

\subsection{Introduction}

In order to identify and analyze the role and impact of the ecosystem approach in a regulatory setting, it is useful to begin with an attempt to explain the origin of this concept and how it is understood in this particular context.

The overall purpose of the ecosystem approach in regulation can be seen as originating from environmental adaptive management and governance. ${ }^{9}$ The concept of ecosystem approach refers to a comprehensive science-based approach to the conservation and management of natural resources. ${ }^{10}$ Initiatives aimed at creating flexible and dynamic legal instruments have become increasingly common as a response to the development of theories of environmental governance and management. ${ }^{11}$ However, its origins in environmental management may also be the cause of difficulties encountered when trying to transfer the concept into a legal context.

The ecosystem approach has become the basis for a gradual and perceptible evolution of new normative tools to shape the way the law is interpreted and applied. It has successively become a legal concept and, as such, a tool for legal governance, which focuses specifically on ecological prerequisites and environmental governance features. It aims to take into account the multi-level

9 E.g. H Wang, 'Ecosystem Management and Its Application to Large Marine Ecosystems: Science, Law, and Politics' (2004) 35 OceanDev\&IntlL 41.

10 Ibid., 42off.

11 Ibid., (n 9); EA Kirk, 'The Ecosystem Approach and the Search for An Objective and Content for the Concept of Holistic Ocean Governance' (2015) 46:1 OceanDev\&IntlL 33. See also Bohman (n 3) 74-79. 
dynamics and scale typical of modern regulatory and institutional structures. ${ }^{12}$ While an ecosystem approach has long been a central perspective in environmental management and policy, this approach is still new to the legal setting. The holistic approach connected to the concept challenges the legal structures. The dynamic and adaptive measures entailed are not always seen as compatible with general principles and structures of law..$^{13}$

In integrating the ecosystem approach, generally much focus has been on adaptive management and flexibility in order to match the ecosystem dynamics of both continuous change and multi-level interaction. Such legal approaches have received much critique. ${ }^{14}$ There are some important obstacles and issues to resolve in order to implement adaptive management and ecosystem governance in law, as well as in clarifying how to ensure that this kind of regulation is compatible with fundamental principles of law, especially those connected to the rule of law. Problems connected with ecosystem approach, as identified above, are inter alia related to institutional coordination, flexible requirements that are hard to enforce, and, not least, the complexity of ecosystem factors. Despite critique and potential obstacles, the legal structure or measures, through which the ecosystem approach is implemented can, however, help the overcome some of the mentioned obstacles and problems. This is the case, if the concept of ecosystem approach is understood as a concept building on more features than just adaptive management and flexibility. The governance perspective added by the theoretical framework of social-ecological resilience is important in this regard. By including features that also creates inter alia stability, redundancy, transparency, and control as part of the system, the ecosystem approach becomes an important part for the achievement of holistic, dynamic perspectives in environmental regulation. The Baltic Sea regulatory regime serves as an important example in this regard.

12 R Long, 'Legal Aspects of Ecosystem-Based Marine Management in Europe' in A Chircop, ML McConnell and S Coffen-Smout (eds), 26 Ocean YB (Brill Niijhoff 2012). See also Bohman (n 3) generally.

13 AK Nilsson and B Bohman, 'Legal prerequisites for ecosystem-based management in the Baltic Sea area: The example of eutrophication' (2015) 44:3 Ambio 370; Bohman (n 3) $74-88$ and generally, the issue is discussed with support in the environmental governance theories of social-ecological resilience.

14 See e.g. MJ Angelo, 'Harnessing the Power of Science in Environmental law: Why We Should, Why We Don't, and How We Can' (2008) 86 TexLRev 1527, 1548; TH Profeta, 'Managing without a Balance: Environmental Regulation in Light of Ecological Advances' (1996) 7 DukeEnvtl L\&Pol'y F 71, 86ff. For a general discussion see also Bohman (n 3) $74-81$. 


\subsection{Background and Application}

The concept of ecosystem approach was formally accepted in $1995^{15}$ when it was adopted by the Conference of the Parties (COP) to the 1992 Convention of Biological Diversity ${ }^{16}$ (the CBD). Since then, its interpretation and application have primarily been developed in guidelines and principles adopted by the COP-CBD. ${ }^{17}$ To date these guidelines and principles are the only formal explanations of how to interpret and understand the ecosystem approach.

According to the CBD, the ecosystem approach '(...) is a strategy for the integrated management of land, water and living resources that promotes conservation and sustainable use in an equitable way (...). ${ }^{18}$ In addition, it is stated in the $\mathrm{CBD}$ description that the ecosystem approach '(...) requires adaptive management to deal with the complex and dynamic nature of ecosystems and the absence of complete knowledge or understanding of their functioning. Ecosystem processes are often non-linear, and the outcome of such processes often shows time-lags. ${ }^{19}$ Despite the fact that these guidelines and principles are developed as part of the СвD regime, they are still authoritative for the interpretation and application of the concept of ecosystem approach also in other regulatory contexts since they are the only formal statements to date. Hence, these guidelines and principles also provide a basis for understanding the concept within HELCOM. ${ }^{20}$ Such interpretation is supported by the 1969 Vienna Convention on the law of treaties ${ }^{21}$ (the Vienna Convention), which states that recourse may be had to supplementary means of interpretation if the general rule of interpretation in Article 31 of the Vienna Convention is not sufficient to determine

15 СвD, The Second Meeting of the Conference of the Parties of the Convention on Biological Diversity, held in Jakarta, Indonesia (СвD COP 2), Decision 8, UNEP/CBD/COP/2/19, 12.

$16 \quad 1760$ UnTS 79.

17 See F Platjouw, Environmental Law and the Ecosystem Approach: Maintaining Ecological Integrity Through Consistency In Law ([E-book] Routledge 2016), ch 2, for an overview of the legal development of the concept.

18 СвD, Description of the ecosystem approach, cop Convention on Biological Diversity, May 200o, in Nairobi, Kenya (CBD, COP 5) Decision v/6, para. 4-5, part A, 1.

19 Ibid., 4.

20 Description and principles of the Ecosystem Approach were presented at: CBD, COP 5 as SBSTTA 5 Recommendation v/10, January/February 2000. Further development of the concept has also been made, e.g. in 2004: CBD, 'The Ecosystem Approach - Operational and Implementation Guidelines', Seventh Ordinary Meeting of the Conference of the Parties to the Convention on Biological Diversity, February 2004 in Kuala Lumpur, Malaysia (CBD COP 7), Decision VII/11, UnEP/CBd/COP/DEC/ViI/11. See also The CBD Malawi Principles, СвD сор Convention on Biological Diversity, May 2000, in Nairobi, Kenya (СвD, COP 5), Decision v/6, para. 4-5, part B. 1155 UNTS 331. 
the meaning of a requirement. ${ }^{22} \mathrm{HELCOM}$ has also directly referred to the CBD in its own implementation and integration of the concept. ${ }^{23}$

As is evident from the СBD definition and description of the concept of ecosystem approach, it manifests a need for both adaptive and precautionary approaches in regulation and thus indirectly introduces a new way of applying these environmental law principles which is more adjusted to complex environmental problems. The ecosystem approach, for example, takes account of uncertainty and change in referring to the absence of complete knowledge and its promotion of adaptive management, sustainable use and integrated management. This can be seen as an expression of the precautionary principle, since the ecosystem approach requires the creation of sustainable structures for management despite lack of full knowledge, and that the design of these structures shall have ecosystem dynamics as a foundation. ${ }^{24}$

The most specific definitions and management principles for the application of the concept of ecosystem approach as developed by the СвD are found in the Malawi principles, adopted by the СвD in 1998 in order to further elaborate and define what the ecosystem approach is. ${ }^{25}$ These principles set out focus points for how management is to be pursued in combination with guidance on how to operationalize an ecosystem approach. ${ }^{26}$ The management principles contain statements that are relevant to how the ecosystem approach is to be applied and focus to a large extent on continuous monitoring in multi-level institutional structures. The principles also clarify the objectives and aims of the ecosystem approach, while introducing a number of basic points of departure for management. ${ }^{27}$ Among these principles is the focus on adaptive management to foresee and cater for ecosystem changes. Another basic point is that the ecosystem approach entails management that should take into account the uncertainties and potential changes that are inherent

22 The Vienna Convention, Article 32. See also U Linderfalk, On The Interpretation of Treaties: The Modern International Law as Expressed in the 1969 Vienna Convention on the Law of Treaties ([E-book] Law and Philosophy Library, vol 83, Springer 2007) 239.

23 HELCOM, 'Statement on the Ecosystem Approach to the Management of Human Activities Towards and Ecosystem Approach to the Management of Human Activities' Adopted at the First Joint Ministerial Meeting of the Helsinki and ospar Commissions (JMM) Bremen, 25-26 June 2003, Agenda item 6, Annex 5 (Ref. §6.1).

24 See the perspective on this by: A Trouwborst, 'The Precautionary Principle and the Ecosystem Approach in International Law: Differences, Similarities and Linkages' (2009) 18:1 RECIEL 26. See also Bohman (n 3$) 83-85$.

25 The CвD Malawi Principles ( СвD, COP 5) Decision v/6, para. 4-5, part B (n 2o).

26 СвD 'The Ecosystem Approach - Operational and Implementation Guidelines' (CBD COP 7), Decision VII/11, UNEP/CBD/COP/DEC/VII/11 (n 20).

27 The CBD Malawi Principles (n 20). 
in so-called social-ecological systems. ${ }^{28} \mathrm{~A}$ significant statement is, moreover, the requirement that the conservation of ecosystem structure and functioning should be a priority target of the ecosystem approach in order to maintain ecosystem services. ${ }^{29}$ The principles also emphasize that measures should be implemented at appropriate spatial and temporal scales. ${ }^{30}$ Management should be decentralized to the lowest appropriate level and involve all socalled stakeholders. ${ }^{31}$ The varying scales and lag effects that characterize ecosystem processes suggest that objectives for ecosystem management should be set for the long term. ${ }^{32}$

The manner in which these various features and principles of the ecosystem approach should be implemented or operationalized in practice in a legal setting is not specified. Since implementation of an ecosystem approach should be dynamic and based on the specific conditions in the particular ecosystem concerned, there can be no universal method for its application. However, some specifics in the different functions, features and principles, such as those described in the Malawi Principles, can be identified in other guidelines on operationalization. ${ }^{33}$ These principles or features show similarities and can be compared to principles of environmental management theories generally, and especially to theories of social-ecological resilience, as mentioned above. ${ }^{34}$ Based on the governance theories that builds on the theoretical framework of social-ecological resilience, they can provide further information on how to make an ecosystem approach more concrete in terms of features that will be necessary in a system aiming to adopt an ecosystem approach. Features that, against this background, can be seen as characteristic of an ecosystem approach in a legal setting, include: flexible and adaptive measures with cyclical review mechanisms; multi-leveled or even polycentric regulatory structures; public participation; and strong connections to ecosystem indicators or variables in the choice of regulatory measures. ${ }^{35}$ What such features mean in terms of legal regulation, and what value they bring, will be further discussed below in relation to the situation in the Baltic Sea region.

$28 \quad$ Ibid. Principles 9 and 10.

29 Ibid. Principle 6.

$30 \quad$ Ibid. Principle 7.

31 Ibid. Principle 2.

32 Ibid. Principle 8. On the operationalization of the ecosystem approach see also: Nilsson and Bohman (n 13).

33 сво 'The Ecosystem Approach - Operational and Implementation Guidelines' (n 20).

34 See e.g. Nilsson and Bohman (n 13)374-75; Bohman (n 3) 29-62, 81-82. See also: C Folke, 'Resilience: The emergence of a perspective for social-ecological systems analysis' (2006) 16:3 Global Envtl Change, 253.

35 See (n 8). 


\subsection{Institutional Development}

The Helsinki Convention ${ }^{36}$ in its present version was revised in 1992 and entered into force in 2000. The agreement is formulated with a certain ambiguity in its provisions, and in a manner that gives states a wide margin for interpretation. The main obligation on states under the Helsinki Convention is to: (...) take all appropriate legislative, administrative or other relevant measures to prevent and eliminate pollution in order to promote the ecological restoration of the Baltic Sea Area and the preservation of its ecological balance. ${ }^{37}$ This is a rather typical formulation for an international agreement, but could still be regarded as a feature that includes the flexibility that is one of the identified characteristics of an ecosystem approach. In addition, the Helsinki Convention has a well-developed system for amending its contents when necessary through the adoption of Annexes and so-called Recommendations; another typically adaptive feature. Although these features are not intentionally implemented to match the concept of ecosystem approach, they can certainly contribute to its implementation. ${ }^{38}$

Another important change in the revised convention is the inclusion of general environmental law principles, such as the precautionary principle, the principle of best available technique and best environmental practice, and the requirement to apply environmental impact assessments. ${ }^{39}$ The environmental law principles are also important mechanisms for implementing the ecosystem approach in different ways. In particular, the ecosystem approach essentially includes the precautionary principle, in the sense that the ecosystem approach can be seen as indirectly introducing a new and more adjusted way of applying the precautionary principle to complex environmental problems such as eutrophication. Furthermore, many of the environmental law principles specifically represent and are intentionally adopted to establish adaptive and flexible mechanisms in a legal system, mechanisms that are also characteristically connected to the concept of the ecosystem approach in a legal context.

In addition to the coastal states, the EU also became a Party to the Helsinki Convention when it was revised in 1992. At that time some of the parties to

\footnotetext{
$36 \quad 2099$ UnTS 195.

37 The Helsinki Convention, Article 3(1).

38 See further in Bohman (n 3 ) 107-17.

39 For an overview of changes of the revised Helsinki Convention, see e.g. J Ebbesson, 'A Critical Assessment of the 1992 Baltic Sea Convention' (2000) 43 German YB of Intl $\mathrm{L} 38,38 \mathrm{ff}$.
} 
HELCOM were already EU member states, while others joined the EU later. At present, eight out of the nine HELCOM state parties are member states of the EU, the exception being the Russian Federation. This means that the EU has significant legislative impact in the region. The EU is also party to a number of regional seas conventions with aims that are similar to those of the Helsinki Convention. ${ }^{40}$ To further implementation of these agreements, in general, the EU has adopted a legal act with significance for the marine environment, the MSFD. Additionally there are several other directives with varying objectives that contribute to the protection of the marine environment in addition to a number of directives that more indirectly contribute to the environmental protection of coastal areas and marine waters.

In 2000 the EU adopted the Water Framework Directive ${ }^{41}$ (the WFD). The WFD is goal-oriented in its structure with an ecosystem-focus in a way that is generally considered to represent an ecosystem approach. The main focus of the WFD is to protect the quality of waters on the landward side of the baseline, more specifically inland surface waters, transitional waters, coastal waters and groundwater. ${ }^{42}$ The goal-oriented structure means that the member states are primarily obliged to adopt River Basin Management Plans and programs with measures being suggested as those that are necessary to achieve the environmental objectives. ${ }^{43}$ The WFD also integrates a number of more area specific directives that regulate different land-based activities that may also affect marine waters and which are to be accounted for in the River Basin Management Plans. ${ }^{44}$ The WFD is thus not primarily aimed at protecting marine waters. Nevertheless, given the physical inter-connections between river

$40 \quad$ E.g. B Bohman and D Langlet, 'Float or Sinker for Europe's Seas? - The Role of Law in Marine Governance', in M Gilek and K Kern (eds), Governing Europe's Marine Environment. Europeanization of Regional Seas or Regionalization of EU Policies? (Ashgate Publishing 2015).

41 Directive 2000/6o/EC of 23 October 2000 establishing a framework for Community action in the field of water policy (the Water Framework Directive) OJ L327/1.

42 The different types of waters are more specifically defined and categorized in the Directive for the purpose of differentiated water governance: WFD, Articles 1 and 2 (and Article 4).

43 WFD, Articles 13, 11 and 4.

44 Directive 91/271/EEC of 21 May 1991 concerning wastewater and discharges from certain industrial sectors (the Urban Waste Water Treatment) OJ L135/40; Directive 91/676/EEC of 12 December 1991 that aims to prevent nitrates from agricultural sources from polluting ground and surface waters (the Nitrates Directive) OJ L375/1; Directive 96/61/EC of 24 September 1996 concerning integrated pollution prevention and control (IPPC) OJ L257/26, now replaced by Directive 2010/75/EU of 24 November 2010 on industrial emissions (integrated pollution prevention and control) (the Industrial Emissions Directive) (IED) OJ L334/17, regarding limitations and prevention of industrial emissions. 
basins, coastal waters, and marine waters, the pollution control and other measures that the WFD prescribes do have effect in marine waters. Hence, although the main focus and aim of the WFD is not marine waters it still regulates landbased sources that can have important effects in and on marine areas.

More relevantly, in 2008, the EU adopted a directive with direct focus on marine waters, the MSFD. The MSFD is also a goal-oriented instrument which is geographically complementary to the WFD as it regulates waters on the seaward side of the baseline. ${ }^{45}$ The main obligation for the member states according to the MSFD is to provide a marine strategy, according to a strict timetable, and to eventually adopt a program of measures that they deem necessary for achieving the goal. This program shall also include activities that are required or accounted for within the WFD and River Basin Management Plans. The ambition in adopting the MSFD was to create a more forceful regulatory regime for the protection of the marine environment in all of the EU, and to further coordinate different EU legal acts with the aim of reducing pollution and protecting marine waters. ${ }^{46}$

This diversity of legal instruments, involved states, and over-arching organizations in the Baltic Sea region illustrate a feature of diversity and plurality that could be seen as inherent in an ecosystem approach. From an ecosystem governance point of view the idea with diverse requirements and plural institutions is, in theory, to create a better base for effective measures and thus increase the likelihood of success. This is based on the assumption that if a number of measures are taken in parallel they may be complementary, or even more importantly, supplementary to each other. If one measure taken does not reach the goal set, then perhaps another measure taken with the same aim will be successful. However, in a legal structure, parallel measures do not work quite in this manner. Rather, parallel legal requirements are generally implemented by only one regulatory solution, especially if the margin of discretion is wide, although they may provide increased incentives for taking measures, as well as for making sure that the goal is achieved. ${ }^{47}$ Moreover, parallel instruments and institutions may also have deviating forms of mechanisms for control and self-reporting, which may be complementary in a way that increase effectiveness in monitoring and control. ${ }^{48}$ Hence, even if the legal system

45 MSFD, Article 2(1).

46 A general presentation of the background, purpose and application of the MSFD is found in: R Long, 'The Marine Strategy Framework Directive: A New European Approach to the Regulation of the Marine Environment, Marine Natural Resources and Marine Ecological Services' (2011) 29:1 JERL 1.

47 Bohman (n 3) 231-40.

48 Ibid., $231-51$. 
reflects these features somewhat differently than how they are seen as part of more general governance, they could still also contribute to a more effective regulatory system.

These diverse, pluralistic, adaptive, flexible and multi-level approaches associated with the ecosystem approach have been criticized for containing inherent obstacles to proper implementation. ${ }^{49}$ However, as the case of the regulatory approach to eutrophication in the Baltic Sea demonstrates, there are also examples of how the ecosystem approach really does create initiatives or a basis for more science-based and ecosystem-centered regulation. Although this may also involve complicated regulatory connections and make the possibilities for reviewing legal compliance and enforcement more complex, it also makes way for flexibility and adaptability in the regulatory structures as intended by the ecosystem approach. One mechanism, or feature, connected with the ecosystem approach that may also compensate for environmental complexity and diversity in the legal structure is formalized pathways for participation at different levels in the legal system to compensate for both the regulatory complexity and flexibility. ${ }^{50}$

Both the WFD and the MSFD are significant environmental legal acts not only because of their contribution to the regulatory governance of water and marine areas, but also because of how they are designed. Both directives represent a holistic regulatory approach to environmental governance. They are both goal-oriented framework directives, containing very little detailed regulation. This regulatory design allows space for both flexibility and adaptive approaches to be taken by the member states in their implementation. The directives moreover exhibit an adaptive design arising from their connectedness to the ecosystem and environmental status. Although directives are always binding as to the result to be achieved, these directives are flexible in the way that they leave much to be defined by the different member states when it comes to the specific measures needed to achieve their goal. This may not necessarily differ very much from how the main obligation of the Helsinki Convention is formulated, which also leaves a large margin of discretion to the state parties, but in the case of the WFD and the MSFD there is

49 The EU WFD has in particular been discussed in these terms. See for example: M Lee, 'Law and Governance of Water Protection Policy' in J Scott (ed), Environmental Protection - European Law and Governance (Oxford University Press 2009) 36ff; H Josefsson and L Baaner, 'The Water Framework Directive - A Directive for the Twenty-First Century?' (2011) 23:3 JEL 463; N Voulvoulis, KD Arpon and T Giakoumis, 'The EU Water Framework Directive: From great expectations to problems with implementation' (2017) 575 Sci Total Environ 358.

Bohman (n 3) 271-76. 
one important difference in how requirements are formed and evaluated. The obligations of the WFD and the MSFD are based on a rather advanced system of different forms of involvement of experts and other actors (referred to as stakeholder participation), ${ }^{51}$ this system also depends on cooperation with scientific experts in a manner that captures much of the intention and features connected to the concept of ecosystem approach. These features, which constitute an important part of the design of these instruments, also establish a system for adaptive review with direct connection to scientific knowledge and environmental data. This new approach is, itself, close to what could be understood to be an ecosystem approach, especially as reflected in the more concrete exampled found in theories of social-ecological resilience. This objective is also confirmed by the fact that the MSFD also states that it should be implemented through an ecosystem-based approach, although it does not further specify specifically what this means. ${ }^{52}$

\subsection{Spatial Scale and Institutional Coordination}

From the perspective of international law and governance, one aspect of the ecosystem approach is particularly interesting. The ultimate aim of an ecosystem approach is to take into account the ecosystem integrity and spatial scales associated with the natural components of the system. As a result, management measures will not primarily take into account administrative or jurisdictional boundaries. Basically, the spatial scale of management must extend across different biological units and legal jurisdictions to encompass an entire ecosystem. In this way, the concept of ecosystem approach also becomes a tool for transboundary law, institutional coordination and cooperation across state borders where the ecosystem does not align with jurisdictional boundaries. This is particularly true in the case of international common-pool resources..$^{53}$ Therefore, it has also been argued that in addition to being a scientific and legal issue, implementation of the ecosystem approach in transboundary common-pool resources - such as the Baltic Sea - is also a political choice. The bridging of jurisdictional conflicts is mainly a political issue which represents one main challenge for the ecosystem approach in shared areas, where its effective application relies on collective political will and the mutual cooperation of the states concerned. ${ }^{54}$ In the Baltic Sea this kind of trans-jurisdictional

$5^{1} \quad$ The term stakeholder is a wide concept that does not always match the more narrow definition of actor involvement and public participation aimed at in a legal context, however it is the term generally applied in relation to ecosystem approach, EU law and in the context of the BSAP, and thus will be the chosen term also in this text.

53 H Wang (n 9) 44.

54 Ibid., 61. 
coordination and cooperation is rather successfully organized by HELCOM and the EU, but it would not have been possible without a political push in this direction through adoption of the legal instruments creating a platform for coordination.

The MSFD is a rather unique instrument in this regard because it requires regional implementation with a specific recommendation to use existing international structures. ${ }^{55}$ In this way it can, at least partly, be seen as reflecting the political choices that are needed to bridge the administrative and judicial boundaries that may constitute borders for framing a relevant ecosystem. In order to achieve such coordination the MSFD calls on the member states to use: '(...) existing regional institutional cooperation structures, including those under Regional Sea Conventions, covering that marine region or sub-region.56 Direct reference is made to, inter alia, the Baltic Sea as one of the marine regions that is relevant for the application and implementation of the directive. ${ }^{57}$ One of the reasons for this requirement is that the international institutions involve non-member states and geographic areas extending beyond EU waters. The regional seas conventions, or the combination of international and EU law, thus have better potential to match the relevant scale of the ecosystem. It is therefore not possible to achieve the aims of the MSFD and to regulate EU marine waters without the transboundary and trans-jurisdictional cooperation of these non-member states. In comparison to other marine areas in the EU the Baltic Sea coastal states are to a large extent also bound by EU law, since it is only Russia that is not an EU member state. ${ }^{58}$ Still, this requirement in the MSFD has initiated important changes and new efforts in the work pursued by HELCOM. Most significantly, in 2007 the HELCOM parties adopted the BSAP as a platform for regional implementation and support for the implementation of the MSFD in the Baltic Sea area. ${ }^{59}$ Through these institutional structures and combinations of legal regimes and instruments, a significant

55 MSFD, Article 6. Also Directive 2014/89/EU of the Council of 23 July 2014 establishing a framework for maritime spatial planning (the MSPD) OJ L257/135 follows the structure of the MSFD and also includes a similar request of integrating international pre-existing structures, such as regional conventions, see Article 11(2)a.

56 MSFD, Article 6(1).

57 MSFD, Article 4(1)a.

$5^{8}$ See e.g. J van Leeuwen, L van Hoof and J van Tatenhove, 'Institutional ambiguity in implementing the European Union Marine Strategy Framework Directive' (2012) 36 Mar Policy 636 .

59 This is apparent in the statements made in the Joint HELCOM-OSPAR Ministerial Meeting, held in Bremen 2003, HELCOM, 'Declaration of the Joint Ministerial Meeting (JMM) of the Helsinki and ospar Commissions', JMM 2003/3(final version)-E, agenda item 6; The aim to coordinate the work of the BSAP with the EU MSFD is also made clear in the preamble of the BSAP. 
dynamic multi-level legal structure is also taking form, including regulation on global, regional/EU, and sub-regional levels, connected through implementation down to national and sub-national/local regulation. Thus, also in this way do the Baltic Sea regulations represent important features of the ecosystem approach as part of structure also reflecting resilience governance.

A significant element in the effectiveness of this approach is institutional coordination and participation from different kinds of stakeholders aimed at eliminating obstacles or incoherent connections between the different regulatory layers and their requirements. Additionally, stakeholder participation contributes to both safeguarding implementation and compliance and to important transfer of knowledge and other information, important for the regulatory process. ${ }^{60}$ Both the MSFD and the BSAP were, themselves, adopted through processes involving wide stakeholder participation, including a range of actors and experts and they also in their design provide structures for continued such participation in the pursuit of their goals and aims. ${ }^{61}$

The inter-connectedness of the EU and HELCOM through the MSFD and the BSAP is an important factor in institutional coordination; it also creates a unique situation with respect to interpretation and implementation of the requirements of these instruments. Admittedly, the BSAP has somewhat uncertain legal status. It is only an action plan and thus not a directly legally binding instrument in its own right, a fact which further complicates the regulatory situation. Nevertheless, as discussed below, the BSAP has, despite its legally uncertain status, become a valuable contribution to the implementation of an ecosystem approach in the Baltic Sea region. With a design similar to that of the MSFD, the BSAP is thus an adaptive and flexible instrument with an inherent structure for participation by different actors, experts and other interest groups. It can also be seen as an extension of the aim of the Helsinki Convention, and as a tool for transferring the Convention requirements into an ecosystem approach. The combination of the MSFD and the BSAP has thus created a basis for an entirely new regulatory structure in the Baltic Sea region, different from that previously established solely by the Helsinki Convention.

\subsection{Regulatory Instruments with Ecosystem Focus}

Despite the inherent differences between the numerous instruments applicable to the Baltic Sea environment, the Helsinki Convention, the BSAP, the MSFD, and the WFD all have similar aims and, although in different ways,

6o Bohman (n 3) 271-305.

61 See e.g. BSAP Segment on Awareness raising and capacity building, 30. See also: $<w w w$ .helcom.fi/baltic-sea-action-plan/partners-in-action/> accessed 2 January 2018. 
their aims are focused on the ecosystem. This is, in part, a result of the political choice to create prerequisites for institutional coordination. The Helsinki Convention aims to promote '(...) ecological restoration of the Baltic Sea and the preservation of its ecological balance.62 The BSAP, which rests on the socalled HELCOM vision, states its aim as being the achievement of good environmental status. ${ }^{63}$ HELCOM adopted the common vision as part of a strategy for implementing and integrating an ecosystem approach into its own convention structures. ${ }^{64}$ This vision is meant to be the platform on which to construct a system to assess ecosystem quality. ${ }^{65}$ The BSAP is partly intended as an instrument to operationalize the vision of good environmental status and an ecosystem approach within the HELCOM regime. The purpose and structure of the MSFD are similar to the BSAP and its aim is also the achievement of good environmental status. ${ }^{66}$ The overall goal of the WFD is similarly good ecological and chemical status, but the structure and design of the WFD is somewhat different. ${ }^{67}$ While the WFD is often referred to as a legal structure integrating an ecosystem approach, it does not directly state this as an aim, while both the MSFD and the BSAP expressly articulate the aims of ecosystem approach or applying an ecosystem-based approach. ${ }^{68}$

The general goals of ecological and environmental status in the WFD, the MSFD and the BSAP are also elaborated in more specific goals, and they are furthermore defined as targets and indicators by which the ecosystem can be

62 The Helsinki Convention, Article 3(1).

63 The aim is to reach HELCOM's vision for good environmental status in the Baltic Sea: BSAP Eutrophication segment, 7 .

64 HELCOM declares the connections between EU legislation, the CBD, the HELCOM Vision, its Ecological Objectives and the BSAP and furthermore states that the BSAP is the tool of implementation of an ecosystem approach in: HELCOM, 'HELCOM Ecological Objectives for an Ecosystem Approach', document for HELCOM Stakeholder Conference on the Baltic Sea Action Plan, Helsinki, Finland, 7 March 2006, if. See also the preamble of BSAP recalling the HELCOM vision.

65 Ibid. See also HELCOM, 'Future role of HELCOM and its organizational structure', Minutes of the 25th Meeting Helsinki, Finland 2-3 March 2004, HELCOM 25/2004, Agenda Item 7.1, Annex 14.

66 MSFD, Article 1(3).

67 According to its Article 1, the WFD defines as its purpose the protection of inland surface waters, transitional waters, coastal waters and groundwater. In order to achieve this, ecological objectives are set out in Article 4. A general requirement for ecological protection, and a general minimum chemical standard, was introduced to cover all surface waters in relation to the ecological objectives. Two elements of 'good ecological status' and 'good chemical status' were then defined. These are elaborated in Annex v of the Water Framework Proposal, in terms of the quality of the biological community, hydrological characteristics and chemical characteristics.

MSFD, Article 1(3) and the BSAP Preamble. 
assessed. All of the instruments have wide applicability and include several issue areas. The definition of good environmental and ecological quality in the BSAP and the MSFD with regard to the specific goal on eutrophication is to have 'minimized human-induced eutrophication' and '(...) a sea unaffected by eutrophication (...)' ${ }^{\prime} 9$ These goals are further translated into ecological objectives that are meant to characterize a marine ecological status which is unaffected by human-induced eutrophication. The chosen objectives are: concentrations of nutrients close to natural levels; clear water; natural level of algal blooms; natural distribution and occurrence of plants and animals; and natural oxygen levels. ${ }^{70}$ In addition, these ecological objectives are also further defined into indicators by which the ecosystem status can be specifically assessed in relation to eutrophication. These assessments are to be made both by each state but also in cooperation and coordination with other state parties and/or member states. ${ }^{71}$ In part, this process is supported by the EU MSFD Common Implementation Strategy but this is also one of the main tasks for the coordinating organization - in this case HELCOM - to handle. ${ }^{72}$

In this way, it is also possible to identify a further step towards a more integrated ecosystem approach within the BSAP and the MSFD in comparison to the Helsinki Convention. The Helsinki Convention also takes ecosystem status - or ecological balance - as its ultimate aim, but this is not further defined. The objectives related to the MSFD and the BSAP are instead intended to create a foundation for more precise indicators and assessments, in order to more precisely assess related and relevant measures. As stated above, the main obligation for states is to take measures that they deem necessary to achieve the

69 BSAP Eutrophication segment, 'Ecological Objectives'; MSFD, Article 3(5) and Quality descriptor in Annex I, Qualitative descriptors for determining good environmental status, p (5): 'Human-induced eutrophication is minimised, especially adverse effects thereof, such as losses in biodiversity, ecosystem degradation, harmful algae blooms and oxygen deficiency in bottom waters.' Furthermore, the WFD is formulated and structured differently than the BSAP or the MSFD, but is still related and not differing much in interpretation. Annex V of the WFD, sets out the criteria for good ecological (and chemical) status in accordance with the directive. In its general definitions of the water status it states that high status equals: '(...) no, or only very minor, anthropogenic alterations to the values of the physico-chemical and hydromorphological quality elements (...)' see WFD, Annex V, 1.2, Normative definitions for ecological status, Table 1.2.

70 BSAP Eutrophication segment.

71 MSFD, Articles 5(1) and 5(2).

72 EU MSFD CIS, The Common Implementation Strategy for the Marine Strategy Framework Directive, 'Learning the lessons and launching a re-enforced phase of implementation', Strategic document including a work programme for 2014 and beyond, Final version agreed by Marine Directors on 5/12/2013. See also Bohman (n 3) 154-59, 231-49. 
regulatory goal of the instrument. ${ }^{73}$ The basis for these measures within the MSFD is a common method for making assessments and the ecosystem indicators. ${ }^{74}$ However, while this might be beneficial from an ecosystem point of view, and paves the ground for both flexibility and adaptability in regards to current problems and levels of knowledge, the effectiveness of this process has also been questioned. However, it is in fact a rather effective process in the way that it has brought the state parties into a common process of implementation based on close cooperation and political focus. In short, this system can be seen as institutionalizing adaptive features and ecosystem focus within the regulatory system, as a result of - and with an important basis in - the steady process of negotiating and evaluating environmental status and ecological indicators. Even if making environmental assessments and defining suitable indicators is a thorough process, this is also one of the more vulnerable aspects of institutional coordination. This is because different factors may be taken into account and thus it is not certain that states have based their assessments on the same indicators. This aspect is also related to differences in structure between the WFD and the MSFD.

Even if the process of adopting and coordinating indicators and making assessments is successful it does not guarantee that states will, in fact, take the necessary measures. This is both related to the difficulties for the EU Commission and HELCOM in scrutinizing what each state has taken into account when deciding on measures, and to the difficulties caused by the lack of any linear and direct relationship between indicators, measures and environmental or ecological change. Thus, the effectiveness of such ecosystem indicator-based regulatory approach and the general aim to achieve good environmental status is questioned because of the leeway that this system gives the states. ${ }^{75} \mathrm{In}$ relation to the issues of effectiveness, it is noteworthy that there is a difference between indicators for status assessment of good environmental status on the one hand, and targets or indicators to track progress towards good environmental status and evaluate effectiveness of measures on the other. Since eutrophication is signified by non-linear causal connections between the input of discharges and the change in the ecosystem, a reduction in pollution cannot be connected to a direct change in the environmental status. There is thus no straightforward connection between indicators for assessing environmental status and measures taken. Instead, effectiveness is more likely to be achieved if focus is also directed towards measures taken.

73 BSAP Eutrophication segment, 6; MSFD, Article 5(2)b.

74 MSFD, Articles 5(1) and 5(2)a.

75 See further in Bohman (n 3 ) 236-49. 
The BSAP does, however, include an even more precise goal in relation to the ecosystem and eutrophication than the MSFD: it has translated the ecological objectives into reduction targets for nutrients. The reduction targets are based on calculations of how large reductions in nutrient pollution would be necessary to achieve the goal of good environmental status for eutrophication, i.e. to have a Baltic Sea which is unaffected by eutrophication. The targets are set in relation to each of the Baltic Sea basins ${ }^{76}$ and in relation to each of the states in the catchment area, so that each state has their own target in relation to their previously monitored discharge levels. Although the legal status of the BSAP is ambiguous and the reduction targets are stated only in principle, the targets do provide a very concrete view of what level of ambition the states must aspire to in taking measures. Since the BSAP is a regional reflection of the MSFD this could be seen as a concretization of the general goal and obligations to take measures also within the MSFD. In this way the BSAP reduction targets are significant in creating more direct application of the ecosystem approach in relation to requirements and measures taken, despite its flexible and uncertain legal status, and despite the actual reduction targets being non-binding.

\section{5 \\ Operationalization and Assessment of Regulatory Measures}

\subsection{Assessing Compliance}

One drawback of the Helsinki Convention and the flexible HELCOM structure is that it does not include any mechanism for strict compliance control concerning the Convention and its related instruments or recommendations. An agreement with high flexibility and a lack of effective compliance control could be regarded as a weak agreement, lowering the level of the trust between the parties. However, it is not only flexibility and the legal status of the Baltic Sea instruments that create uncertainties in relation to enforcement and compliance when it comes to eutrophication and other similar environmental problems. Flexible structure and legal uncertainty are important factors to take into account when reviewing the prerequisites for compliance and how to assess what is actually required by an instrument. In other words - if requirements

76 The Baltic Sea is divided in a series of sub-basins separated by sills. The main sub-basins are the Bothnian Bay, the Bothnia Sea, the Archipelago Sea, the Gulf of Finland, the Gulf of Riga, the Baltic Proper, the Belt Sea, Kattegat, and the Danish Straits. See R Elmgren, 'Understanding Human Impact on the Baltic Ecosystem: Changing Views in Recent Decades' (2001) 30:4/5 Ambio, Man and the Baltic Sea, 222. 
are wide and undefined in precise terms it is difficult to judge what to require compliance with.

This relationship between requirements and compliance becomes even more diffuse if the requirements - as in the case of Baltic Sea eutrophication are connected to ecosystem indicators that are hard to trace. It is questionable whether it is sufficient to have a legal structure that is so directly connected to ecosystem assessments, particularly when it is an undisputed fact that it is not possible to trace environmental change and environmental progress as a linear outcome of any measures taken. If the object of regulation is also difficult to monitor - like diffuse nutrient pollution - there are opportunities to free-ride. ${ }^{77}$ This means that state parties may choose a low ambition of implementation and compliance and rely on other states to take measures to ensure a better environmental status in the Baltic Sea - or at least not get caught - since it is not possible to hold such state accountable for non-compliance. Another reason for slow development of traceable results and a significant risk of non-compliance may be found in the fact that vagueness of the obligations makes compliance difficult to determine. ${ }^{78}$ Thus while the new legal instruments and structures are designed to apply an ecosystem approach and be more directly connected to ecosystem status, there is also a risk that they create a system in which it is not possible to asses legal compliance and enforcement. These aspects will be addressed in the following sections.

\subsection{Monitoring Environmental Data and Scientific Information}

The flexibility and loose structure described could lead to uncertainties in regard to compliance. However, as noted above, connecting regulatory efforts to ecosystem indicators and scientific knowledge are important features of an ecosystem approach. It is clear that ecosystem management through implementation of an ecosystem approach should be based on the contemporary scientific understanding of the relevant ecosystem. Such scientific understandings can be gained through international cooperation, including through joint scientific research, exchange of information, knowledge and experience, transfer of technology, etc. ${ }^{79}$ One reason these aspects are important, in addition to the increased ecosystem focus and scientific basis they create, is that the actual system itself creates a platform for closer cooperation between states

77 K Raustiala, 'Form and Substance in International Agreements' (2005) 99:3 AJIL 581, $592-93$.

78 See further in: EA Kirk, 'Noncompliance and the Development of Regimes Addressing Marine Pollution from Land-based Activities' (2008) 39:3 OceanDev\&IntlL 235, $239 f f$. 
to find mutual solutions and thus also puts focus on issues that are difficult to solve, such as diffuse pollution and regulatory measures in the agricultural sector. In short, it creates a platform for a process of some kind of managerial compliance. In this way the collaboration connected to ecosystem indicators and the actual ecosystem approach also bears the potential to bridge some of the uncertainty connected to adaptive management approaches within the regulatory structure and flexible mechanisms.

The Helsinki Convention has developed requirements in this regard, and calls on the parties to, inter alia, cooperate in the fields of science, technology and research, and to exchange data and scientific information. ${ }^{80}$ The Convention also provides for the adoption of monitoring programs, and HELCOM thus monitors both the pollution load in the whole marine area, including open waters, as well as the sources of this pollution in the Baltic Sea area. In the 1980 s HELCOM introduced regular data collection to document the ecological status of the Baltic Sea in so-called Pollution Load Compilations (PLC). ${ }^{81}$ In 1990, an important step was taken when the Joint Comprehensive Environmental Action Programme (JCP) was adopted at a ministerial meeting. The program identified a list of hot spots and actions to be taken in relation to these hot spot problems. ${ }^{82}$ These initiatives by HELCOM have been important for the development of the regulatory structure in the Baltic Sea area, even if they have not been directly connected to an assessment of compliance or measures taken by the parties. Indeed, on the contrary, HELCOM has built its compliance review on self-reporting, although this has not proven to be a very effective mechanism. The reports that HELCOM has received from states parties regarding measures and implementation of amendments and recommendation have been varying in detail and quality. As a result of these varying and sometimes incomplete reports it appears that HELCOM has not had a complete picture of the level of compliance with its suggested measures. Hence it has also not been possible to review whether measures taken and their proper implementation can be connected to certain environmental improvements or not. ${ }^{83}$

\footnotetext{
8o The Helsinki Convention, Article 24(1).

81 These are the so-called нецсом Pollution Load Compilations (PLCs). The first PLC: HELCOM (1987) 'First Pollution Load Compilation', Baltic Sea Environmental Proceedings (BSEP) No. 20, 1987. See also the Fifth Baltic Sea Pollution Load Compilation: Helcom, 'The Fifth Baltic Sea Pollution Load Compilation (PLC-5) - An Executive Summary', Baltic Sea Environmental Proceedings, No. 128A, 2012. See also Bohman (n 3) 128-31.

82 Inter alia: M Valman, Three Faces of HELCOM - institution, organization, policy producer (159 Stockholm Studies in Politics, Stockholm University 2014) 16.

83 Bohman (n 3) 192-196, 339-47.
} 
Another reason for why implementation, compliance and the reporting on measures taken have been at a low level could be that many of the problem areas and the suggested measures have been controversial for the states to enforce on a national level. This seems also to be a reason why it has been difficult in the first place to agree on hard requirements. One problematic area, in particular, is diffuse pollution from agriculture and the measures recommended to reduce this pollution through reductions and adjustments in agricultural practices. ${ }^{84}$

The engagement and initiatives to strengthen marine governance within the EU have also had a significant impact on the development of further regulatory action among the Baltic Sea coastal states and on the integration of the ecosystem approach. This action has, however, to a large extent built on the previously gathered data and scientific experience of HELCOM which has assisted in providing necessary information relating to the determination of environmental status. HELCOM has thus had a significant role in the development and application of the EU directives in the Baltic Sea setting. It has also been crucial in elaborating the reduction targets in the eutrophication segment of the BSAP. ${ }^{85}$

Nevertheless, although HELCOM has been continuously monitoring the environmental status of the Baltic Sea and has issued recommendations to its parties based on its findings, these assessments have not been as directly connected to ecosystem change in the way that the MSFD and BSAP propose. One significant result of adopting the MSFD and the BSAP has been the focus on environmental indicators, and the much important work of making environmental assessments and reassessments that has followed. These assessments have been made both in order to identify or define what good environmental status is, i.e. what is to be accomplished, and to determine the current environmental status in relation to this goal. This also includes the identification of indicators which may be used to track environmental change and can possibly therefore be used as connecting points with the measures that have been or should be taken.

\footnotetext{
84 E.g. HeLcom Terms of Reference for HeLCom Group on Sustainable Agricultural Practices (adopted by неLсом ноD 46-2014). See also нецсом, Updated Fifth Baltic Sea Pollution Load Compilation (PLC-5.5), Baltic Sea Environmental Proceedings No 145, 2015, for a description of the distribution of pollution sources.

85 BSAP, Eutrophication segment, 8-9; also ibid., 145 .
} 


\subsection{Pathways for Participation}

In legal regimes and structures generally, participation or involvement of actors representing the public, NGOS, experts, and interest groups (here referred to as stakeholders $)^{86}$ occurs in many different ways through both formal and informal channels. In recent decades, international law, national legal regimes and the EU have increasingly supported and included mechanisms and structures for different kinds of stakeholder involvement. ${ }^{87}$ Participation is acknowledged as a means to, inter alia, balance international, multilateral, and multileveled norms with local action, in a democratic spirit. ${ }^{88}$ This corresponds to what has been stated in elaborations of the concept of ecosystem approach in the СвD. The guiding principles developed for the implementation of the ecosystem approach emphasize stakeholder participation and the exchange of knowledge and information. ${ }^{89}$

The provisions of the Helsinki Convention do not directly address the issue of stakeholder participation. Article 17 of the Convention states that the parties shall ensure that information on the condition of the Baltic Sea and the waters in its catchment area is made available to the public, as well as information on measures taken or planned. However, development of the BSAP involved a process of stakeholder involvement, and the structures established by the MSFD and the BSAP envisage participation by different actors, not least scientific experts. As a result HЕLCOM has also updated its guidelines on granting

86 'Stakeholder' is generally seen as broad term for defining interest groups, and does not match the more strictly defined group of actors usually targeted by formal requirements for participation in legal regimes.

87 See for example: S Charnovitz, 'Two Centuries of Participation: NGOs and International Governance' (1997) 18 MichJIntlL 183; M Ambrus, K Arts, E Hey and H Raulus, 'The role of experts in international and European decision-making processes: setting the scene' in M Ambrus, K Arts, E Hey and H Raulus (eds), The role of "experts" in international and European decision-making processes: advisors, decision makers or irrelevant actors? (Cambridge University Press 2014); J Ebbesson, 'Public Participation' in D Bodansky, J Brunnée and E Hey (eds), The Oxford Handbook of International Environmental Law (Oxford University Press 2007) 681-702.

88 Ebbesson (n 87) 686ff; L Schrefler, 'Reflections on the different roles of expertise in regulatory policy making' in M Ambrus, K Arts, E Hey and H Raulus (eds), The role of "experts" in international and European decision-making processes: advisors, decision makers or irrelevant actors? (Cambridge University Press 2014). See also for example the conclusions of: $S$ Andresen, "The role of scientific expertise in multilateral environmental agreements: influence and effectiveness' in M Ambrus, K Arts, E Hey and H Raulus (eds), The role of "experts" in international and European decision-making processes: advisors, decision makers or irrelevant actors? (Cambridge University Press 2014).

89 The CвD Malawi Principles (n 20), Principles, 1, 2, 7 and 11. 
observer status to its meetings. ${ }^{90}$ The guidelines now state, inter alia, that: 'The organization must be able to contribute substantially to the aims and objectives of the organization and must be able to contribute substantially to the aims and objectives of the Commission. It must have technical, scientific, economic, social or other expertise relevant to the objectives of the Convention on the Protection of the Marine Environment of the Baltic Sea Area. ${ }^{91}$

The process of decision-making in the Baltic Sea legal frameworks, and not least the process of adopting ecological indicators and targets as well as all the work associated with development and implementation of these instruments, demands and involves a large variety of actors who bring different types of knowledge, including scientific knowledge, to the process. Some changes and developments regarding stakeholders and participation have been seen with regard to the BSAP. The process leading towards the adoption of the BSAP stressed the importance of stakeholder participation, as an important factor in the concept of ecosystem approach..$^{92}$ This is thus also reflected in the implementation or operationalization of the ecosystem approach and the BSAP, where a more direct approach towards stakeholder participation is integrated. In contrast to the Helsinki Convention, the BSAP deals with this subject in more detail. ${ }^{93}$ It is also clear that the foundations of the BSAP - the ecological assessments and indicators - have been developed through rather advanced collaboration with, inter alia, scientists in a stakeholder process. ${ }^{94}$ For the purpose of implementing the BSAP and the MSFD, HELCOM has established working groups and strategies in order to steer its work in the direction of further involvement of scientific experts and other stakeholders. Some examples will be reviewed in the following section.

\subsection{Adaptive and Managerial Approaches to Implementation}

An important change that has been brought by the new structure of thorough assessments, reassessments and definition of indicators, is that it necessitates greater cooperation between science and state parties. Another feature

9o HeLCOM Guidelines on Granting Observer Status to Intergovernmental Organizations and International Non-Governmental Organizations to the Helsinki Commission, 36-2015, Annex 14.

91 Ibid., criteria 1.3.

92 HelCOM 'Statement on the Ecosystem Approach to the Management of Human Activities Towards and Ecosystem Approach to the Management of Human Activities' (n 23), para 15 a.

93 BSAP Segment on Awareness raising and capacity building, 30.

94 See for example: SD Van Deveer, 'Networked Baltic Environmental Cooperation' (2011) 42:1 Journal of Baltic Studies 37, 42. 
in these instruments, including the WFD, is that they are objects of cyclic adaptive evaluation and assessment. The plans and programmes of measures adopted must be kept up to date and be re-evaluated within a certain interval (every 6 years). ${ }^{95}$ This leads to further and continuous state cooperation and also to recurring meetings within both the framework of the MSFD and the BSAP. Thus the new regulatory structure has already led to more intensified collaborations between the parties and with a new range of stakeholders. These meetings and evaluations of measures might also lead to further assessments, further recommendations adopted by HELCOM and hopefully further measures (or other measures) adopted by the states. ${ }^{96}$

HELCOM has also updated its work on monitoring and assessment based on a Strategy that was adopted by the HELCOM Ministerial Meeting in 2013. ${ }^{97}$ The Strategy is a common plan to monitor and assess the health of the Baltic Sea in a coordinated and cost-efficient way involving all HELCOM contracting parties. Some of the objectives of the monitoring and assessment strategy include laying out a system which enables showing how visions, goals and objectives set for the Baltic Sea marine environment are being met; providing a system that enables linking the quality of the environment to its management - even if this is not possible in relation to eutrophication - and; facilitating the implementation of the ecosystem approach covering the whole Baltic Sea, including coastal and open waters.

The Strategy furthermore sets out the structure and time frame for the production of region-specific assessments such as comprehensive thematic and holistic assessments and more concise and more timely indicator reports and other assessment products. Moreover, the Strategy aims to create a system to enable the raising of general public awareness of the Baltic Sea and HELCOM actions. The general principles of the monitoring strategy that relate to coordinated monitoring have been translated into concrete specifications and requirements through the HELCOM Monitoring Manual. ${ }^{98}$

HELCOM has also established a special working group to implement the ecosystem approach, the Group for the Implementation of the Ecosystem Approach (HELCOM GEAR). GEAR is meant to work towards region-wide cooperation on all elements of national marine strategies, building both on national

\footnotetext{
95 MSFD, Article $17(2)$.

96 See also Bohman (n 3) 277-310, 356-65.

97 HELCOM Monitoring and Assessment Strategy, part of the 2013 HelCom Ministerial Declaration and was adopted by the 2013 HELCOM Ministerial Meeting, Attachment 4 of the document was updated in 8.9.2017 following decisions made in STATE \& CONSERVATION 6-2017 meeting.

Ibid.
} 
activities based on a legal framework and on HELCOM's work, including HELCOM's coordinated monitoring programmes, core indicators with good environmental status boundaries, and thematic and integrated assessment reports. The group also reviews strategies and environmental indicators with the view to facilitating adaptive management to improve the status of the Baltic Sea. ${ }^{99}$

HELCOM GEAR not only implements the BSAP but also serves as a regional instrument for the national work of the HELCOM EU contracting states in implementing the EU MSFD. It acts as a managerial level coordinator and includes coordination with activities under the Maritime Doctrine ${ }^{100}$ of the Russian Federation, the Russian instrument that compares to the MSFD and the BSAP. ${ }^{101}$ In practice GEAR is intended to plan activities that support regional coordination and activities on the ecosystem approach. GEAR also serves as an initiator of processes and reviews the relevant deliverables to guarantee that these have an optimal timing and content and respond to management and policy needs. GEAR facilitates the work and decision-making of the Heads of Delegation (HOD), allowing the HOD to focus on more strategic and policy relevant issues. ${ }^{102}$

Another step taken when building new regulatory structures and implementing both the ecosystem approach and, more specifically, the MSFD and the BSAP, is the establishment of The HELCOM Group on Sustainable Agricultural Practices (Agri Group). HELCOM has always worked with issues relating to pollution from agriculture but with the adoption of the BSAP more force was put into this issue area. The Agri Group was established to deal specifically with agriculture in relation to the implementation of the ecosystem approach. The group is charged with finding solutions to how the agricultural sector can further contribute to reaching good environmental status. The group thus involves representatives from agriculture and environment authorities of the Baltic Sea states, the EU, and the HELCOM Observers (or Stakeholders) in a joint discussion on the Baltic agriculture and provides a platform for the creation of policy measures and instruments aimed at reducing the environmental impact

99 HELCOM, Terms of Reference for Hецсом Group on the Implementation of the Ecosystem Approach, As agreed by the HELCOM Heads of Delegation on 17 September 2014.

100 Maritime Doctrine of Russian Federation 2020, in English (unofficial translation): $<$ https://dnnlgwick.blob.core.windows.net/portals/o/NWCDepartments/Russia\%20 Maritime\%2oStudies\%2oInstitute/Maritime\%2oDoctrine\%2oTransENGrus_FINAL.pdf? $\mathrm{sr}=\mathrm{b} \& \mathrm{si}=\mathrm{DNNFileManagerPolicy \& sig=fqZgUUVRVRrKmSFNMOj \% 2FNaRNawUoRdhdv}$ pFJj7\%2FpAkM\% ${ }_{3} \mathrm{D}>$ accessed 2 September 2018. See also <http://en.kremlin.ru/events/ president/news/50060>.

101 HELCOM, Terms of Reference for HELCOM Group on the Implementation of the Ecosystem Approach (n 99).

102 Ibid. 
of agriculture, to the eutrophication, in the Baltic Sea. ${ }^{103}$ HELCOM thus has increasing cross-sectorial collaboration on agricultural issues, ensuring multivoiced discussions aimed at furthering prosperity from agriculture across the region, but still with the objective of minimizing harm to the Baltic Sea. One explicit aim of the Agri Group is to facilitate implementation of Part II of Annex III of the Helsinki Convention on 'Prevention of Pollution from Agriculture'. The group meets at least once a year, in order to support and follow-up the implementation and progress of the BSAP, including the so-called 'Palette of measures for reducing phosphorus and nitrogen losses from agriculture' that was adopted together with the 2013 Copenhagen Ministerial Declaration. ${ }^{104}$ In addition, HELCOM has also pursued projects with the more specific goal of establishing better environmental practices in agriculture in certain targeted states. ${ }^{105}$ Some projects have been directly bilateral with Russia in regards to their implementation of the BSAP, since Russia is not an EU member state. Some projects have also been collaborating with non-party states (being neither parties to the Helsinki Convention, nor members to the EU) but that are part of the catchment area, primarily Belarus. ${ }^{106}$ Such projects could also be included in the work of the Agri Group.

These aspects of the new regulatory structures, with reviews, wider participation and collaboration as presented above, are interesting because they require deeper involvement by the state parties both in taking a more proactive role in the process of developing and implementing measures, and in the development of new law. While self-reporting has been the main mechanism for compliance review within HELCOM, the new system of adaptive review and reporting of measures taken both to HELCOM and to the European Commission constitutes a more thorough process. The states are required to report on their measures and on evaluations of these measures as a part of the implementation process. In addition, the results are continuously assessed and discussed in the cyclic review process where progress is to be tracked and elaborated. Importantly, there is a double incentive structure since the state parties

\footnotetext{
103 Terms of Reference for HELCom Group on Sustainable Agricultural Practices (n 84) 1.

104 Ibid., 1.

105 See e.g. Baltic Compass Project, <www.helcom.fi/helcom-at-work/projects/completed -projects/baltic-compass/> accessed 2 January 2018 and $<$ www.balticcompass.org/index .html $>$ accessed 2 January 2018.

106 E.g. HELCOM BALthaZAR (2009-2012), <www.helcom.fi/helcom-at-work/projects/ completed-projects/balthazar/> accessed 2 January 2018 and HELCOM BASE (2012-2014), $<$ www.helcom.fi/helcom-at-work/projects/completed-projects/base/>accessed 2 January 2018.
} 
are obligated both by the Helsinki Convention and the BSAP, as well as by the EU Directives.

The establishment of new working groups and routines resulting from the adoption of the BSAP does not in itself explain any developments in regulation and/or measures. However, one may assume that having a group of experts that focuses specifically on developing alternative measures and practices, and which, moreover, works actively to include stakeholders and authorities within the entire region, will have at least some effect, resulting in further suggested measures and potential solutions, as well as in increased pressure on the state parties to implement such measures and solutions. In this way GEAR, in particular, can be seen as fostering managerial compliance, since its mandate is clearly to foster coordination on a managerial level among the states. ${ }^{107}$

Through the work of both GEAR and the Agri Group important bridges that balance politically sensitive issues are being built. Even though there are requirements of pollution reductions from agricultural practices in Annex III to the Helsinki Convention, the state parties have been reluctant to implement such requirements strictly. The development of reductions from agriculture has been slow. ${ }^{108}$ Nevertheless, it was repeated in the BSAP that pollution from agriculture must be reduced since it is one of the main sources of nutrients, and new Recommendations were adopted. ${ }^{109}$ No hard laws have, however, been agreed upon. This is undoubtedly is partly because it is difficult to define in any precise way what each state must do in order to reduce pollution from agriculture, but it is also likely to be because of the economic interests that are tied to effective agricultural production as well as strong lobbying groups. It is arguably more useful to apply adaptive approaches in the manner now being done and to work through these groups in a coordinated fashion to bridge some of the politically sensitive issues that arise. At the very least this method of operation can involve both state representatives and general stakeholders in a process that focuses more on solutions rather than on obstacles. Through this collaborative process of review and control the risks entailed with the flexibility of the regulatory instruments, which could provide

107 A Chayes and AH Chayes (n 1) (generally) and 10-11. See also Kirk, EA, 2008 (n 78), 236, where the author argues that a regime's strength in part can be derived from the manner in which it responds to noncompliance if noncompliance is embraced as part of an iterative process of developing understanding, knowledge, capacity, etc.

108 See e.g. Helcom 2015, Updated Fifth Baltic Sea Pollution Load Compilation (PLC-5.5) Baltic Sea Environment Proceedings, No. 145, 2015.

109 HELCом Copenhagen Ministerial Declaration: Taking Further Action to Implement the Baltic Sea Action Plan - Reaching Good Environmental Status for a healthy Baltic Sea, 3 October 2013, Copenhagen, Denmark; BSAP Eutrophication Segment. 
a leeway for freeriding or choosing less ambitious levels of implementation, are also to some extent being compensated without setting the legal principles aside, and while still enabling the kind of adaptive and flexible approaches that are required by an ecosystem approach. ${ }^{110}$ Moreover, this combination of control, focus on mechanisms for a governance system with prerequisites to allow for adjustments to the ecosystem dynamics, multi-level processes, as well as involvement of relevant actors might provide regulatory governance structures for the achievement social-ecological resilience as presented by the current theoretical framework. ${ }^{111}$

As noted above, these institutional developments have essentially resulted in a review structure that resembles a managerial compliance process. ${ }^{112}$ Many of the stakeholders involved are those who will be directly affected by new regulatory measures. This can be criticized since it is likely that these actors might create obstacles to stricter measures. However, it also means that the level of acceptance of any measures that are adopted becomes higher, and acceptance is often a good basis for implementation and compliance. ${ }^{113}$

This process of developing 'managerial compliance' has allowed the further development of solutions to issues that have resisted regulation through the more traditional law-making processes. Thus, in this way, the ecosystem approach, and the features or functions it entails, have had an important impact on the overall regulatory structure and legal development. Although the ecological indicators cannot always be directly connected or used as a tool for evaluating measures, the process of developing both measures and ecological indicators has led to a regulatory process that is directly connected to the ecosystem. This structure and process are also clearly both based on and dependent on features such as participatory pathways and adaptive review which leads to flexibility, science-based measures, and a more active review of enforcement and implementation.

The aim of this chapter has been to review and present some aspects of the impact of the ecosystem approach in the regulation of eutrophication in

110 Bodansky (n 2) 250-51. See also PM Haas, 'Do regimes matter? Epistemic communities and Mediterranean pollution control' (1989) 43(3) Int Organ 377, where similar development in the governance of the Mediterranean is described.

111 See Bohman (n 3), ch 8.

112 As defined in A Chayes and AH Chayes (n 1); Bohman (n 3) 323-26, 356-72.

113 See for example: C Abbot and M Lee, 'Economic Actors in EU Environmental Law' (2015) 34:1 YEL 26. See also Bohman (n 3) 303-o6. 
the Baltic Sea. The purpose has been to show how features of environmental governance, reflecting an ecosystem approach, may be identified within a legal framework. The purpose has also been to demonstrate how the implementation of such features not only leads to a genuinely more ecosystem-focused regulatory system, but may also create provisions for a more effective implementation of regulatory requirements - even where there is a general lack of traditional compliance review mechanisms. Indeed, in fields of environmental law involving complex, non-linear problems, this might even be considered a more effective structure since it also provides for a review system where focus is on measures taken rather than on only trying to identify results.

Many of the features that typically represent an ecosystem approach are reflected in the current regulatory setting in the Baltic Sea. However, the vagueness and flexibility of the obligations expressed leaves considerable leeway to states in deciding on specific measures to be adopted to implement their obligations. This is equally true in the case of the Helsinki Convention as in the case of the EU Directives, opening the possibility of a lowering of ambition when it comes to the measures to be adopted. However, some features of the regulatory framework, including pathways for participation and more ecosystem-centered regulatory approaches, seem to strengthen the overall regulatory structure and, thus, the integration of an ecosystem approach. Nevertheless, it must be acknowledged that not all states in the Baltic Sea catchment area are parties to HELCOM or member states of the EU. They are thus not bound by HELCOM or EU requirements, although they may still be included in the principal reduction targets, which are themselves problematic as they are established on a state by state basis rather than collectively. More effective collaborative solutions are needed to address these shortcomings, and it is possible that these new structures can pave the way for such bilateral cooperation.

Legal frameworks for regulating the discharge of eutrophic substances in the Baltic Sea area can be seen to provide a good basis for adopting new and stronger legal measures adjusted to the complexity of eutrophication. The legal instruments contain requirements for the Baltic Sea coastal states to take further measures and they also aim at promoting further cooperation and coordination in the region. ${ }^{114}$ HELCOM and the Helsinki Convention have produced a large number of Recommendations as a complement to the Convention provisions, with more specific demands for measures required and emphasis on other types of actions to reduce the nutrient input to the Baltic Sea. ${ }^{115}$ In

\footnotetext{
114 MSFD, Article 6, preamble (13) and (16); the BSAP Eutrophication segment.

115 Helcom Recommendations: 28E/4, Revised Annex III 'Criteria and Measures Concerning the Prevention of Pollution from Land-Based Sources', of the 1992 Helsinki Convention
} 
addition, the reduction targets in the BSAP have contributed to the whole legal structure by concretizing what good environmental status actually means and, additionally, what level of measures must be taken into account to eliminate pollution consistently with the obligations of the Helsinki Convention.

The most important change that can be connected to the ecosystem approach, however, seems to be the development of a process for making ecosystem assessments at different levels; a process that includes suggesting measures and identifying what kind of regulatory actions might lead to the desired result. This has created a basis for what can only be described as a managerial compliance process that seems to bridge many of the uncertainties arising from the regulatory structure and the complex environmental factors it seeks to address. This platform for assessments and discussions has provided advancements in areas where solutions are complex and where agreement on legally binding measures has been difficult, or impossible, to obtain. Nevertheless, the issues of time-lags between measures taken and visible results, and of adoption of effective operational targets, offer real challenges even with a managerial system in place. When all is accounted for, however, it seems likely that both the level of ambition for state implementation and the level of requirements will rise.

\section{Table of Authorities}

\section{Treaties}

The 1969 Vienna Convention on the law of treaties (the Vienna Convention) 1155 UNTS 331

The 1992 Convention on Biological Diversity, 1760 UNTS 79

The 1992 Convention on the Protection of the Marine Environment of the Baltic Sea

Area (The Helsinki Convention) 2099 UnTS 195

(Part II: Prevention of Pollution from Agriculture), Adopted 15 November 2007 having regard to Article 20, Paragraph 1 c) of the Helsinki Convention; 28E/5, Municipal Wastewater Treatment, Adopted 15 November 2007 having regard to Article 20, Paragraph 1 b) of the Helsinki Convention; 28E/6, On-site wastewater treatment of single family homes, small business and settlements up to 300 person equivalents (p.e.), Adopted 15 November 2007 having regard to Article 20, Paragraph 1 b) of the Helsinki Convention; 28E/7, Measures aimed at the substitution of polyophates (phosphorus) in detergents, Adopted 15 November 2007 having regard to Article 20, Paragraph 1 b) of the Helsinki Convention. 


\section{EU Directives}

Council Directive 91/271/EEC of 21 May 1991 concerning urban waste-water treatment (Urban Waste Water Treatment Directive) OJ L135/ 40 (Amended by Commission Directive 98/15/EC of 27 February 1998 with respect to certain requirements established in Annex I thereof OJ L67/29)

Council Directive 91/676/EEC of 12 December 1991 concerning the protection of waters against pollution caused by nitrates from agricultural sources (Nitrates Directive) OJ L375/1

Council Directive 96/61/EC of 24 September 1996 concerning integrated pollution prevention and control OJ L257/26

Directive 2000/6o/EC of the European Parliament and of the Council of 23 October 2000 establishing a framework for Community action in the field of water policy (Water Framework Directive) OJ L327/1

Directive 2008/56/EC of the European Parliament and of the Council of 17 June 2008 establishing a framework for community action in the field of marine environmental policy (Marine Strategy Framework Directive) OJ L164/19

Directive 2010/75/EU of the European Parliament and of the Council of 24 November 2010 on industrial emissions (integrated pollution prevention and control) (the Industrial Emissions Directive) OJ L334/17

Directive 2014/89/EU of the European Parliament and of the Council of 23 July 2014 establishing a framework for maritime spatial planning OJ L 257/135

\section{Other Legal Instruments}

Maritime Doctrine of Russian Federation 2020, in English (unofficial translation): <https://dnnlgwick.blob.core.windows.net/portals/o/NWCDepartments/Russia \%2oMaritime\%2oStudies\%2oInstitute/Maritime\%2oDoctrine\%2oTransENGrus_ FINAL.pdf?sr=b\&si=DNNFileManagerPolicy\&sig=fqZgUUVRVRrKmSFNMOj\%2F NaRNawUoRdhdvpFJj7\%2FpAkM\%3D > accessed 2 September 2018.

\section{Bibliography}

\section{Books}

Biggs R, Schlüter M and Schoon ML (eds), Principles for Building Resilience - Sustaining Ecosystem Services in Social-Ecological Systems (Cambridge University Press 2015).

Bodansky D, The Art and Craft of International Environmental Law (Harvard University Press 2010).

Bohman B, Transboundary Law for Social-Ecological Resilience? A Study on Eutrophication in the Baltic Sea Area (Stockholm University US-AB 2017). 
Chapin II FS, Kofinas GP and Folke C (eds), Principles of Ecosystem Stewardship: Resilience-Based Natural Resource Management in a Changing World (Springer 2009).

Chayes A and Chayes AH, The New Sovereignty: Compliance with International Regulatory Agreements (Harvard University Press 1995).

Ebbesson J, 'Public Participation' in Bodansky D., Brunnée J. and Hey E. (eds), The Oxford Handbook of International Environmental Law (Oxford University Press 2007).

Linderfalk U, On the Interpretation of Treaties: The Modern International Law as Expressed in the 1969 Vienna Convention on the Law of Treaties ([E-book], Law and Philosophy Library, vol 83, Springer 2007).

Platjouw F, Environmental Law and the Ecosystem Approach: Maintaining Ecological Integrity Through Consistency In Law ([E-book] Routledge 2016).

Valman M, Three Faces of HELCOM - institution, organization, policy producer (159 Stockholm Studies in Politics, Stockholm University 2014).

\section{Official Documents}

СвD, The Second Meeting of the Conference of the Parties of the Convention on Biological Diversity, held in Jakarta, Indonesia (СвD соP 2), Decision 8, UNEP/CBD/ COP/2/19.

СвD, Description of the ecosystem approach, COP Convention on Biological Diversity, May 2000, in Nairobi, Kenya (CBD, COP 5), Decision v/6, para. 4-5, part A.

CвD, Malawi Principles, cop Convention on Biological Diversity, May 2000, in Nairobi, Kenya (CBD, COP 5), Decision v/6, para. 4-5, part B.

СвD СOP5, SBSTTA 5 Recommendation v/10, January/February 2000.

СвD, 'The Ecosystem Approach - Operational and Implementation Guidelines', Seventh Ordinary Meeting of the Conference of the Parties to the Convention on Biological Diversity, February 2004 in Kuala Lumpur, Malaysia (СвD соP 7), Decision VII/11, UNEP/CBD/COP/DEC/VII/11.

EU MSFD CIS, The Common Implementation Strategy for the Marine Strategy Framework Directive, 'Learning the lessons and launching a re-enforced phase of implementation', Strategic document including a work programme for 2014 and beyond, Final version agreed by Marine Directors on 5/12/2013.

HelCOM AGRI, 'Terms of Reference for Helcom Group on Sustainable Agricultural Practices' (adopted by HELCOM HOD 46-2014).

Helcom Baltic Sea Action Plan (BSAP), adopted on 15 November 2007 in Krakow, Poland by the HELCOM Extraordinary Ministerial Meeting.

HELCOM GEAR, 'Terms of Reference for HELCOM Group on the Implementation of the Ecosystem Approach', As agreed by the HELcom Heads of Delegation on 17 September 2014. 
HELCOM, 'Declaration of the Joint Ministerial Meeting (JMM) of the Helsinki and OSPAR Commissions', JMM 2003/3(final version)-E, agenda item 6.

HeLCOM, 'Eutrophication in the Baltic Sea - An integrated thematic assessment of the effects of nutrient enrichment and eutrophication in the Baltic Sea region: Executive Summary', Baltic Sea Environmental Proceedings, No. 115A, 2009.

helcom 'First Pollution Load Compilation', Baltic Sea Environmental Proceedings (BSEP) No. 20, 1987.

Helcom 'Guidelines on Granting Observer Status to Intergovernmental Organizations and International Non-Governmental Organizations to the Helsinki Commission', 36-2015, Annex 14.

helcom, 'Helcom Copenhagen Ministerial Declaration: Taking Further Action to Implement the Baltic Sea Action Plan - Reaching Good Environmental Status for a healthy Baltic Sea', 3 October 2013, Copenhagen, Denmark.

HELCOM, 'HELCOM Ecological Objectives for an Ecosystem Approach', document for HeLcom Stakeholder Conference on the Baltic Sea Action Plan, Helsinki, Finland, 7 March 2006.

Helcom, Minutes of the 25th Meeting Helsinki, Finland 2-3 March 2004, Helcom 25/2004, Agenda Item 7.1, Annex 14, 'Future role of HELCOM and its organizational structure'.

HELCOM, 'Monitoring and Assessment Strategy', part of the 2013 HELCOM Ministerial Declaration, adopted by the 2013 HELCOM Ministerial Meeting, Attachment 4 of the document updated in 8.9.2017 following decisions made in STATE \& CONSERVATION 6-2017 meeting.

H ELCOM Recommendation 28E/4, Revised Annex II 'Criteria and Measures Concerning the Prevention of Pollution from Land-Based Sources', of the 1992 Helsinki Convention (Part II: Prevention of Pollution from Agriculture), Adopted 15 November 2007 having regard to Article 20, Paragraph 1 c) of the Helsinki Convention.

HELCOM Recommendation 28E/5, Municipal Wastewater Treatment, Adopted 15 November 2007 having regard to Article 20, Paragraph 1 b) of the Helsinki Convention.

HELCOM Recommendation $28 \mathrm{E} / 6$, On-site wastewater treatment of single family homes, small business and settlements up to 300 person equivalents (p.e.), Adopted 15 November 2007 having regard to Article 20, Paragraph 1 b) of the Helsinki Convention.

HELCOM Recommendation $28 \mathrm{E} / 7$, Measures aimed at the substitution of polyohates (phosphorus) in detergents, Adopted ${ }_{5}$ November 2007 having regard to Article 20, Paragraph 1 b) of the Helsinki Convention.

Helcom, 'Statement on the Ecosystem Approach to the Management of Human Activities Towards and Ecosystem Approach to the Management of Human 
Activities' Adopted at the First Joint Ministerial Meeting of the Helsinki and osPAR

Commissions (JMM) Bremen, 25-26 June 2003, Agenda item 6, Annex 5 (Ref. §6.1). Helcom, 'The Fifth Baltic Sea Pollution Load Compilation (PLC-5) - An Executive

Summary', Baltic Sea Environmental Proceedings, No. 128A, 2012.

HelCom, 'Updated Fifth Baltic Sea pollution load compilation (PLC-5.5)' Baltic Sea

Environment Proceedings, No. 145, 2015.

\section{Book Chapters}

Ambrus M, Arts K, Hey E and Raulus H, 'The role of experts in international and European decision-making processes: setting the scene' in Ambrus M, Arts K, Hey E and Raulus $\mathrm{H}$ (eds), The role of "experts" in international and European decision-making processes: advisors, decision makers or irrelevant actors? (Cambridge University Press 2014).

Andresen S, 'The role of scientific expertise in multilateral environmental agreements: influence and effectiveness' in Ambrus M, Arts K, Hey E and Raulus H (eds), The role of "experts" in international and European decision-making processes: advisors, decision makers or irrelevant actors? (Cambridge University Press 2014).

Bohman B and Langlet D, 'Float or Sinker for Europe's Seas? - The Role of Law in Marine Governance' in Gilek M and Kern K (eds), Governing Europe's Marine Environment. Europeanization of Regional Seas or Regionalization of EU Policies? (Ashgate Publishing 2015).

Lee M, 'Law and Governance of Water Protection Policy' in J Scott (ed), Environmental Protection - European Law and Governance (Oxford University Press 2009).

Long R, 'Legal Aspects of Ecosystem-Based Marine Management in Europe' in A Chircop, ML McConnell and S Coffen-Smout (eds), 26 Ocean YB (Brill Nijhoff 2012).

Schrefler L, 'Reflections on the different roles of expertise in regulatory policy making' in Ambrus M, Arts K, Hey E and Raulus H (eds), The role of "experts" in international and European decision-making processes: advisors, decision makers or irrelevant actors? (Cambridge University Press 2014).

\section{Journal Articles}

Abbot C and Lee M, 'Economic Actors in EU Environmental Law' (2015) 34:1 YEL 26.

Angelo MJ, 'Harnessing the Power of Science in Environmental law: Why We Should, Why We Don't, and How We Can' (2008) 86 TexLRev 1527.

Charnovitz S, 'Two Centuries of Participation: NGOs and International Governance' (1997) 18 MichJIntlL 183.

Ebbesson J, 'A Critical Assessment of the 1992 Baltic Sea Convention' (2000) 43 German YB of Intl $\mathrm{L}_{3} 8$. 
Elmgren R, 'Understanding Human Impact on the Baltic Ecosystem: Changing Views in Recent Decades' (2001) 30:4/5 Ambio, Man and the Baltic Sea, 222.

Folke C, 'Resilience: The emergence of a perspective for social-ecological systems analysis' (2006) 16:3 Global Envtl Change 253.

Haas PM, 'Do regimes matter? Epistemic communities and Mediterranean pollution control' (1989) 43:3 Int Organ 377.

Josefsson H and Baaner L, 'The Water Framework Directive - A Directive for the Twenty-First Century?' (2011) 23:3 JEL 463.

Kirk EA, 'Noncompliance and the Development of Regimes Addressing Marine Pollution from Land-based Activities' (2008) 39:3 OceanDev\&IntlL 235.

Kirk EA, 'The Ecosystem Approach and the Search for An Objective and Content for the Concept of Holistic Ocean Governance' (2015) 46:1 OceanDev\&IntlL 33.

van Leeuwen J, van Hoof L and van Tatenhove J, 'Institutional ambiguity in implementing the European Union Marine Strategy Framework Directive' (2012) 36 Mar Policy 636.

Long R, 'The Marine Strategy Framework Directive: A New European Approach to the Regulation of the Marine Environment, Marine Natural Resources and Marine Ecological Services' (2011) 29:1 JE RL 1.

De Lucia V, ‘Competing Narratives and Complex Genealogies: The Ecosystem Approach in International Environmental Law' (2015) 27 J Env L 91.

Nilsson AK and Bohman B, 'Legal prerequisites for ecosystem-based management in the Baltic Sea area: The example of eutrophication' (2015) 44:3 Ambio 370.

Profeta TH, 'Managing without a Balance: Environmental Regulation in Light of Ecological Advances' (1996) 7 DukeEnvtl L\&Pol'y F 71.

Raustiala K, 'Form and Substance in International Agreements' (2005) 99:3 AJIL 581.

Trouwborst A, 'The Precautionary Principle and the Ecosystem Approach in International Law: Differences, Similarities and Linkages' (2009) 18:1 RECIEL 26.

VanDeveer SD, 'Networked Baltic Environmental Cooperation' (2011) 42:1 J of Baltic Studies 37 .

Voulvoulis N, Arpon KD and Giakoumis T, 'The EU Water Framework Directive: From great expectations to problems with implementation' (2017) 575 Sci Total Environ 358.

Wang H, 'Ecosystem Management and Its Application to Large Marine Ecosystems: Science, Law, and Politics' (2004) 35 OceanDev\&IntlL 41.

\section{Miscellaneous}

HELCOM Stakeholder platform, <www.helcom.fi/baltic-sea-action-plan/partners-in -action/> accessed 2 January 2018.

Baltic Compass Project, <www.helcom.fi/helcom-at-work/projects/completed -projects/baltic-compass/> accessed 2 January 2018 and <www.balticcompass.org/ index.html $>$ accessed 2 January 2018. 
HELCOM BALTHAZAR (2009-2012), <www.helcom.fi/helcom-at-work/projects/ completed-projects/balthazar/> accessed 2 January 2018.

HELCOM BASE (2012-2014), <www.helcom.fi/helcom-at-work/projects/completed -projects/base/> accessed 2 January 2018. 